\title{
Interaction between genetic diversity and temperature stress on life-cycle parameters and genetic variability in midge Chironomus riparius populations
}

\author{
Christian Vogt ${ }^{1, *}$, Annika Pupp ${ }^{1}$, Carsten Nowak ${ }^{2}$, Lucas S. Jagodzinski ${ }^{1}$, \\ Jonas Baumann ${ }^{1}$, Daniel Jost ${ }^{1}$, Matthias Oetken ${ }^{1}$, Jörg Oehlmann ${ }^{1}$ \\ ${ }^{1}$ Department of Aquatic Ecotoxicology and ${ }^{2}$ Department of Ecology and Evolution, Institute of Ecology, Evolution and \\ Diversity, J. W. Goethe University, Siesmayerstrasse 70, 60323 Frankfurt am Main, Germany
}

\begin{abstract}
The genetic diversity of natural populations and the increase in global temperature are becoming important issues in ecotoxicological research. We investigated the combined effects of 3 different temperature levels and 6 different levels of genetic diversity on the life history parameters of $C h i-$ ronomus riparius. Inbreeding and loss of genetic variation are major threats to small and endangered populations. The reduction of fitness due to inbreeding is more severe under stressful environmental conditions. We show that under even a moderate temperature stress, a decrease in genetic variation has important consequences on the fitness of populations. This indicates that the global temperature increase could have serious effects on the distribution and survival of locally distributed or rare species.
\end{abstract}

KEY WORDS: Life-history parameters · Microsatellites · Diptera · Chironomidae · Genetic impoverishment

Resale or republication not permitted without written consent of the publisher

\section{INTRODUCTION}

A range of biotic and abiotic factors affect the development and reproduction of wildlife populations under field conditions. Within this complex puzzle of different ecological parameters, 2 have become the focus of scientists within the last decade. The increase in temperature due to global warming (Araujo \& Rahbek 2006), and the loss of genetic variability within populations as a result of habitat fragmentation or pollution stress are emerging problems for biodiversity (Bickham et al. 2000, Frankham 2005a). Both parameters affect biological processes at the individual (Frouz et al. 2002) or the population level (Hall \& Burns 2002). The increasing global temperature especially affects ectothermic organisms, which have a limited ability to maintain body temperature at a constant level; hence their growth and development are closely connected to the ambient temperature. Temperature affects ectothermic organisms in 3 different ways: (1) at low temperatures somatic growth is inhibited; (2) at higher temperatures intrinsic population growth rates increase; and (3) beyond a critical threshold temperature a higher mortality rate occurs (Frouz et al. 2002, Pery \& Garric 2006).

The fitness of individuals and populations is also affected by genetic variability, as allelic and phenotypic richness is associated with the survival of populations (Mitton 1997). Rich genetic diversity is important for the long-term survival of populations, especially in changing environments (Frankham 2005a,b). Populations with insufficient genetic variability have less chances to adapt; and the loss of genetic variation is associated with inbreeding (Keller \& Waller 2002, Hansson \& Westerberg 2002). Inbreeding leads to the phenotypic expression of previously rare lethal alleles and thus reduces the fitness within populations. This reduced fitness, termed 'inbreeding depression', is more severe under stressful environmental conditions, e.g. salinity, temperature stress or chemical exposure (Hauser \& Loeschcke 1996, Dahlgaard \& Hoffmann 2000, Armbruster \& Reed 2005). 
The aim of this study was to determine the interaction between temperature stress and inbreeding, using an ectothermic aquatic invertebrate to test if genetically impoverished populations exhibit a higher sensitivity to temperature shifts. We selected a species from the dipterian family of Chironomidae, the non-biting midge Chironomus riparius, representing a model organism with a benthic-associated life cycle. Chironomids are widely distributed in the temperate northern hemisphere and are characterised by a huge ecological tolerance (Armitage et al. 1995). They can be found in hot springs, eutrophic and oligotrophic ponds, lowland rivers, and sub-glacial streams (Pinder 1986). Chironomids have 3 aquatic juvenile (egg, larvae and pupae) and one aerial adult life-stages (Olivier 1971). Previous studies assessing the effect of temperature variation $\left(12-37^{\circ} \mathrm{C}\right)$ on chironomid growth patterns concluded that growth was promoted by increasing temperature up to a certain limit (Sankarperumal \& Pandian 1991, Stevens 1998, Frouz et al. 2002, Pery \& Garric 2006). In contrast, female body size and fecundity decreased with higher temperatures (Frouz et al. 2002, Gong et al. 2002). These studies were all performed with single populations; the additional impact of genetic diversity in connection with the effects of temperature shifts was not investigated. Hence, we tested if the development and reproduction of Chironomus riparius are affected by temperature shifts $\left( \pm 3^{\circ} \mathrm{C}\right)$ and if there is an interaction between these effects and genetic diversity.

\section{MATERIALS AND METHODS}

\subsection{Test organisms}

For the experiments, 6 different Chironomus riparius populations were used (Table 1). One population, with a high inbreeding level (Pop. VI) was obtained from ECT Ecotoxicology, Flörsheim. Five other genetically different populations (Pop. I-V) were derived from different generations of a multi-generation study (under controlled conditions) performed using our inbred inhouse mass culture (GEN-) and a genetically variable population (GEN+). The GEN- population was established in 1998 with egg ropes from the laboratory of Bayer AG, Leverkusen. The diverse population (GEN+) was created in 2004 out of 11 different laboratory stocks from 7 countries (Bulgaria, Germany, France, Finland, Great Britain, Netherlands and USA) (Nowak et al. 2007). All populations, except Pop. VI, were cultured for many generations at a constant temperature of $20^{\circ} \mathrm{C}$. All experiments were conducted at different times within 2 consecutive years under standard laboratory conditions (OECD 2004).
Table 1. Chironomus riparius. Origin, abbreviation and genetic diversity of the populations used for the temperature treatments; Pop. I to V were from an in-house mass culture multi-generation experiment; GEN-: inbred cultures; GEN+: genetically variable crossbreed populations (Nowak et al. 2007). $H_{\mathrm{e}}$ : expected heterozygosity

\begin{tabular}{|lcc|}
\hline Population origin & Abbreviation & $H_{\mathrm{e}}$ \\
\hline Generation 6 GEN+ & Pop. I & 0.536 \\
Generation 8 GEN+ & Pop. II & 0.509 \\
Generation 16 GEN+ & Pop. III & 0.343 \\
Generation 6 GEN- & Pop. IV & 0.226 \\
Generation 8 GEN- & Pop. V & 0.263 \\
ECT Ecotoxicology & Pop. VI & 0.100 \\
(Flörsheim, Germany) & & \\
\hline
\end{tabular}

\subsection{Experimental procedures}

Static life-cycle experiments were conducted according to Vogt et al. (2007a) at 3 different temperatures. The standard temperature of $20^{\circ} \mathrm{C}$ was used as the control treatment and 2 treatments with temperature shifts $\left(17\right.$ and $\left.23^{\circ} \mathrm{C}\right)$ were performed. The animals were cultured in climate chambers (Sorvall Heraeus, Kendor Laboratory Products) from the first larval stage until emergence. For culturing we used $600 \mathrm{ml}$ glass beakers containing $100 \mathrm{~g}$ pure quartz sand (grain size $0.1-0.4 \mathrm{~mm}$ ) and $400 \mathrm{ml}$ reconstituted water. Each treatment consisted of 8 replicates. Prior to the experiment, vessels were prepared with sediment and water and covered with gauze (mesh size $0.75 \mathrm{~mm}$ ); $3 \mathrm{~d}$ before the start of each experiment, freshly laid ( $\leq 24 \mathrm{~h})$ egg ropes were taken from each population. Newly-hatched larvae from different egg ropes were combined to randomly select 20 first instar larvae for each replicate. The larvae were fed with a finely ground fish-food suspension (0.5 mg larva ${ }^{-1} \mathrm{~d}^{-1}$, TetraMin $\left.{ }^{\circledR}\right)$. To compensate for possible temperature differences inside the climate chambers, the position of test vessels was randomized daily. From Day 10, the number of emerged imagines were counted twice daily. Successfully emerged midges were collected with an exhauster and transferred to a breeding container, consisting of a glass aquarium $(30 \times 20 \times 20 \mathrm{~cm})$ closed with a stainless steel gauze (mesh size $0.5 \mathrm{~mm}$ ). Each breeding container was maintained at a constant temperature of $20^{\circ} \mathrm{C}$ and contained a plastic (polypropylene) dish $(11.5 \times 11.5 \times 5.5 \mathrm{~cm})$, filled with $400 \mathrm{ml}$ of reconstituted water for oviposition. The egg-ropes were counted and removed from the breeding container daily. Based on the method described by Vogt et al. (2007a), the number of eggs per clutch were recorded. Each egg-mass was placed in a well of a 24-microwell plate and after $3 \mathrm{~d}$ the fertility was determined. At the end of the experiment (Day 32), dead imagines were collected (only for Pop. I, II, IV and V) and 
dried at $34^{\circ} \mathrm{C}$ for $3 \mathrm{~d}$. The dry body weight of each animal was determined to the nearest $\mu \mathrm{g}$ using a balance (Sartorius 4401).

\subsection{Microsatellite analyses}

For the genetic analyses, 100 first instar larvae from each population were cultured in 1 separate aquarium under the same experimental conditions. As soon as the larvae reached the L4 instar, they were frozen in liquid nitrogen and stored at $-80^{\circ} \mathrm{C}$. Genetic variation was measured at 5 variable microsatellite loci previously identified for Chironomus riparius (Nowak et al. 2006). DNA extraction was performed using a modified standard CTAB (cetyltrimethylammonium bromide) protocol (Winnepenninckx et al. 1993). Microsatellite fragments were amplified on a T3 thermocycler (Biometra) and amplified DNA fragments were diluted $1 / 25$ prior to electrophoretical fragment length analysis on an ALF sequencer (Pharmacia). Alleles were counted using the Alfwin ${ }^{\circledR} 1.0$ software of the same manufacturer. In total, 36 ind. were checked for each combination of population and temperature. The offspring of 2 populations (Pop. I and IV) were reared under the same procedure for an additional generation to determine the genetic diversity of the F1-generation. Pop. IV, with the second lowest genetic diversity, was chosen because in Pop. VI (which had the lowest genetic diversity) a high mortality was observed at $17^{\circ} \mathrm{C}$. Pop. I was selected to represent a population with a high genetic variability.

\subsection{Statistical analysis}

Statistical analyses were performed using the software program GraphPad Prism ${ }^{\circledR}$, Version 4.03 (Graph Pad Software). Based on the emergence time and the number of emerged imagines, the mean emergence time $\left(\mathrm{EmT}_{50}\right)$ was calculated. To calculate $\mathrm{EmT}_{50}$, the natural logarithm $(x)$ of time (in d) was taken and the number of emerged midges was cumulated and normalised to percentages for each replicate $(Y)$. After that, non-linear regression was performed using the logistic curve (b, slope; $c$, maximal response $=100 \%$ ) of which the $\mathrm{EmT}_{50}$ is a parameter. This parameter could only be determined for treatments with mortality rates (non-emerged midges) below 80\%, because in those cases meaningful values were generated.

$$
Y=\frac{C \times \mathrm{e}^{b\left(x-\mathrm{EmT}_{50}\right)}}{1+\mathrm{e}^{b\left(x-\mathrm{EmT}_{50}\right)}}
$$

No replicates were available for the number of eggmasses per female (total and fertile), because emerged adults from all 8 replicates per population and temperature were transferred into one single breeding container to form a swarm of sufficient size. Population growth rate (PGR) was calculated according to a simplified Euler-Lotka calculation based on: mortality rate $(f)$, mean emergence time of females $(g)$, female fraction (h), number of eggs per egg-mass (i) and number of fertile egg-masses per female $(j)$; only one value per population was available.

$$
\mathrm{PGR}=\left[(j \times i \times h) \times\left(1-\frac{f}{100}\right)\right]^{\frac{1}{g}}
$$

Expected heterozygosity $\left(H_{\mathrm{e}}\right)$ was calculated using the Genpop ${ }^{\circledR}$ online version 3.4 software (Raymond \& Rousset 1995) based on the number of loci $(m=5)$, the number of alleles per loci $(k)$ and the allele frequency $\left(p_{i}\right)$.

$$
H_{\mathrm{e}}=\frac{1}{m} \sum_{I=1}^{m} \sum_{i=1}^{k} p_{i}^{2}
$$

All data were tested for normality using the Kolmogorov-Smirnov test. Normal distributed data sets $\left(\mathrm{EmT}_{50}\right.$ and male dry body wt) were checked for significant differences to the corresponding $20^{\circ} \mathrm{C}$ treatment using 1-way ANOVA with Dunnett's post hoc test within single populations. For non-normal distributed parameters (mortality, eggs per egg-mass and female dry body wt) a non-parametric Kruskal-Wallis test with Dunn's post hoc test was applied.

To test the impacts of the 2 combined stressors of temperature and inbreeding on life cycle parameters, a 2-way ANOVA was applied. For the number of eggmasses per female (total and fertile) and the PGR no statistical tests could be applied because there were too few replications.

\section{RESULTS}

\subsection{Genetic diversity}

The genetic analyses indicated that Pop. I had the highest genetic variability of all considered populations (Table 1). In contrast, Pop. III exhibited a much lower genetic variability, explained by the higher inbreeding level resulting from the ongoing multi-generational experiment (Nowak et al. 2007). Therefore, the expected heterozygosity $\left(H_{\mathrm{e}}\right)$ for Pop. I was nearly $1.5 \times$ higher than for Pop. III. All GEN- populations exhibited a clearly decreased level of genetic diversity; the lowest value analysed was for Pop. VI. For that population, the 5 microsatellite loci were nearly homozygotic with an $H_{e}$ of 0.10 . The genetic variability for Pop. IV was lower than for Pop. V, even though the latter was selected from the multi-generation study 2 generations later. 


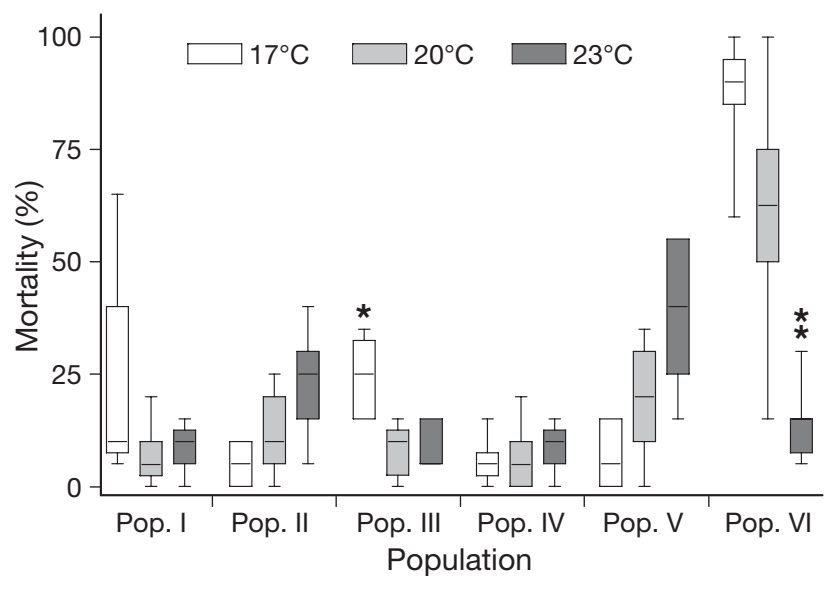

Fig. 1. Chironomus riparius. Median mortality ( $\% \pm 25 / 75$ percentile) of 6 genetically different populations (for descriptions see Table 1). Significant differences were calculated using Kruskal-Wallis test (with Dunnett's post hoc test), comparing treatments of 17 and $23^{\circ} \mathrm{C}$ with the standard treatment at $20^{\circ} \mathrm{C} .{ }^{*} \mathrm{p}<0.05,{ }^{*} \mathrm{p}<0.01, \mathrm{n}=6-12$

\subsection{Mortality}

The mortality rates of Pop. I-V were little affected by temperature stress (Fig. 1) their maximal median mortality rates were $<40 \%$. Only one significantly increased mortality rate at temperature stress was detected (Pop. III; $\left.17^{\circ} \mathrm{C}, \mathrm{p}<0.05\right)$. In contrast, dramatic effects of temperature stress on survival were observed for the population with the lowest genetic variability (Pop. VI). This strain exhibited a very high median mortality rate at $17^{\circ} \mathrm{C}(90 \%)$. Although a high mortality rate was observed for the standard temperature $\left(20^{\circ} \mathrm{C}, 62 \%\right)$, a low mortality rate was observed for the highest temperature $\left(23^{\circ} \mathrm{C}, 15 \%\right)$. For mortality, a clear interaction between temperature stress and inbreeding was calculated $(\mathrm{p}<$ 0.001, Table 2). Furthermore, both genetic variability and temperature were significantly $(\mathrm{p}<0.001$ and $\mathrm{p}<0.01$, respectively) responsible for the variation within the data.

\subsection{Mean emergence time $\left(\mathrm{EmT}_{50}\right)$}

No interaction between genetic diversity and temperature was determined for mean emergence time, but an effect of genetic variability and temperature was found ( $p<0.001$, Table 2). In general, at higher temperatures the animals emerged significantly $(\mathrm{p}<$ 0.001) earlier for all populations (Fig. 2). At $23^{\circ} \mathrm{C}$ the mean emergence time was on average ( $\pm \mathrm{SE}$ ) $36 \%$ $( \pm 1.9 \%)$ compared to the $17^{\circ} \mathrm{C}$ treatments. A linear regression was calculated for the mean emergence time and the temperature for all populations, whereby the correlation coefficients were 0.96-0.99.
Table 2. Two-way ANOVA for the life cycle parameters of 6 genetically different populations of Chironomus riparius at temperatures of 17,20 and $23^{\circ} \mathrm{C}$

\begin{tabular}{|c|c|c|c|c|c|}
\hline Source of variation & $\mathrm{df}$ & SS & MS & $F$ & $\mathrm{P}$ \\
\hline \multicolumn{6}{|l|}{ Mortality } \\
\hline Interaction & 10 & 27650 & 2.765 & 20.3 & $<0.001$ \\
\hline Genetic variation & 5 & 33400 & 6.679 & 49.0 & $<0.001$ \\
\hline Temperature & 2 & 1861 & 9.304 & 6.87 & $<0.01$ \\
\hline \multicolumn{6}{|l|}{$\mathrm{EmT}_{50}$} \\
\hline Interaction & 10 & 57.8 & 5.78 & 0.27 & $>0.05$ \\
\hline Genetic variation & 5 & 515 & 103 & 4.80 & $<0.001$ \\
\hline Temperature & 2 & 1290 & 644 & 30.0 & $<0.001$ \\
\hline \multicolumn{6}{|c|}{ No. of eggs per egg-mass } \\
\hline Interaction & 10 & 238200 & 23.820 & 1.05 & $>0.05$ \\
\hline Genetic variation & 5 & 441900 & 88.380 & 3.91 & $<0.01$ \\
\hline Temperature & 2 & 983000 & 491.500 & 21.7 & $<0.001$ \\
\hline \multicolumn{6}{|c|}{ Dry body wt of males (females) } \\
\hline Interaction & 6 & $\begin{array}{c}0.12 \\
(0.78)\end{array}$ & $\begin{array}{c}0.02 \\
(0.13)\end{array}$ & $\begin{array}{c}13.3 \\
(3.01)\end{array}$ & $\begin{array}{l}<0.001 \\
(<0.01)\end{array}$ \\
\hline Genetic variation & 3 & $\begin{array}{c}0.03 \\
(1.35)\end{array}$ & $\begin{array}{c}0.01 \\
(0.45)\end{array}$ & $\begin{array}{c}7.37 \\
(10.4)\end{array}$ & $\begin{array}{c}<0.001 \\
(<0.001)\end{array}$ \\
\hline Temperature & 2 & $\begin{array}{c}0.71 \\
(0.68)\end{array}$ & $\begin{array}{c}0.36 \\
(0.34)\end{array}$ & $\begin{array}{c}255 \\
(7.83)\end{array}$ & $\begin{array}{c}<0.001 \\
(<0.001)\end{array}$ \\
\hline
\end{tabular}

\subsection{Reproduction}

The total number of egg-masses per female varied between 0.22 (Pop. VI, $17^{\circ} \mathrm{C}$ ) and 1.40 (Pop. IV, 20 ${ }^{\circ} \mathrm{C}$ ). The lowest numbers of total egg-masses per female were observed for Pop. VI at all temperature levels (Table 3). This population exhibited a decreased number of egg-masses per female. High fertility of eggmasses was observed for all populations (with the exception of Pop. VI); $55 \%$ of all laid egg-masses were

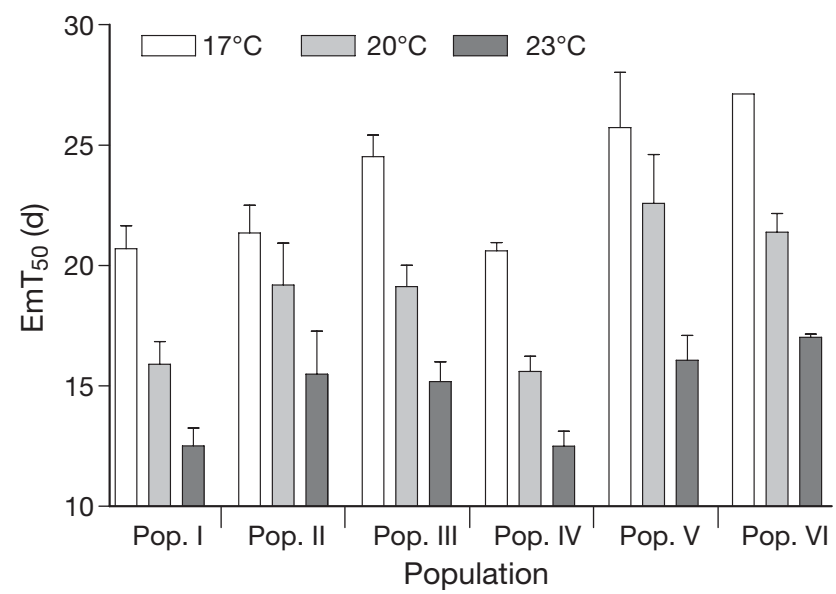

Fig. 2. Chironomus riparius. Mean emergence time (d) $\left(\mathrm{EmT}_{50}\right.$ $\pm \mathrm{SE}$ ) of 6 genetically different populations (for descriptions see Table 1). Significant differences were calculated using 1-way ANOVA (Dunnett's post hoc test), comparing treatments at 17 and $23^{\circ} \mathrm{C}$ with the standard treatment at $20^{\circ} \mathrm{C}$ $(\mathrm{n}=6-12)$. For $\mathrm{EmT}_{50}$ all treatments are significantly different from the $20^{\circ} \mathrm{C}$ treatment 
Table 3. Chironomus riparius. Egg-masses per female (T: total; F: fertile) at 3 temperature treatments for 6 genetically different populations (for descriptions see Table 1)

\begin{tabular}{|lcccccc|}
\hline \multirow{2}{*}{ Population } & \multicolumn{2}{c}{$17^{\circ} \mathrm{C}$} & \multicolumn{2}{c|}{$20^{\circ} \mathrm{C}$} & \multicolumn{2}{c|}{$23^{\circ} \mathrm{C}$} \\
& $\mathrm{T}$ & $\mathrm{F}$ & $\mathrm{T}$ & $\mathrm{F}$ & $\mathrm{T}$ & $\mathrm{F}$ \\
\hline Pop. I & 1.31 & 0.98 & 1.34 & 0.96 & 1.00 & 0.92 \\
Pop. II & 1.00 & 0.77 & 0.93 & 0.51 & 0.67 & 0.39 \\
Pop. III & 0.67 & 0.51 & 0.98 & 0.62 & 1.04 & 0.76 \\
Pop. IV & 0.98 & 0.54 & 1.40 & 0.93 & 0.84 & 0.64 \\
Pop. V & 0.71 & 0.52 & 0.74 & 0.53 & 0.78 & 0.48 \\
Pop. VI & 0.22 & 0.00 & 0.54 & 0.00 & 0.66 & 0.05 \\
\hline
\end{tabular}

fertile. For Pop. VI, no fertile egg-masses were observed at 17 and $20^{\circ} \mathrm{C}$ and the population died out. At $23^{\circ} \mathrm{C}$ only a low number of fertile egg-masses per female were observed (0.05). A 2-way ANOVA could not be applied to the egg-masses per female (total and fertile), because there were not enough replicates. A strong tendency was observed for the fertile number of egg-masses, whereby the populations with lower genetic diversity produced less fertile egg-masses than populations with higher genetic diversity.

For the clutch size, no interaction between genetic variability and temperature was observed, but there was an effect of genetic variability and temperature (Table 2). At higher temperatures, the females produced smaller egg-masses within single populations, and significant differences were calculated for Pop. I, III, IV and V (Fig. 3).

\subsection{Dry body weight of imagines}

Within the single populations, effects of temperature on male dry body wt were measured (Fig. 4). For all populations, significantly ( $p<0.001$ ) lower dry body wt was observed in the $23^{\circ} \mathrm{C}$ treatments. Furthermore, the males had a significantly ( $\mathrm{p}<0.001)$ higher mean dry body wt at $17^{\circ} \mathrm{C}$ than at $20^{\circ} \mathrm{C}$ for Pop. I, IV and V. For females, dry body wt varied between 0.37 and $0.61 \mathrm{mg}$, but no clear effect of temperature stress was detected (data not shown). The results of the 2-way ANOVA indicated for both genders a significant $(p<0.01$, Table 2$)$ interaction between genetic variability and temperature. Furthermore, a significant ( $p<0.001)$ impact from genetic variability and temperature was determined.

\subsection{Population growth rate (PGR)}

At 17 and $20^{\circ} \mathrm{C}$ the females of Pop. VI did not produce fertile egg-masses and thus only at $23^{\circ} \mathrm{C}$ was a PGR determined (Fig. 5). The highest PGR was observed in the population with the highest genetic

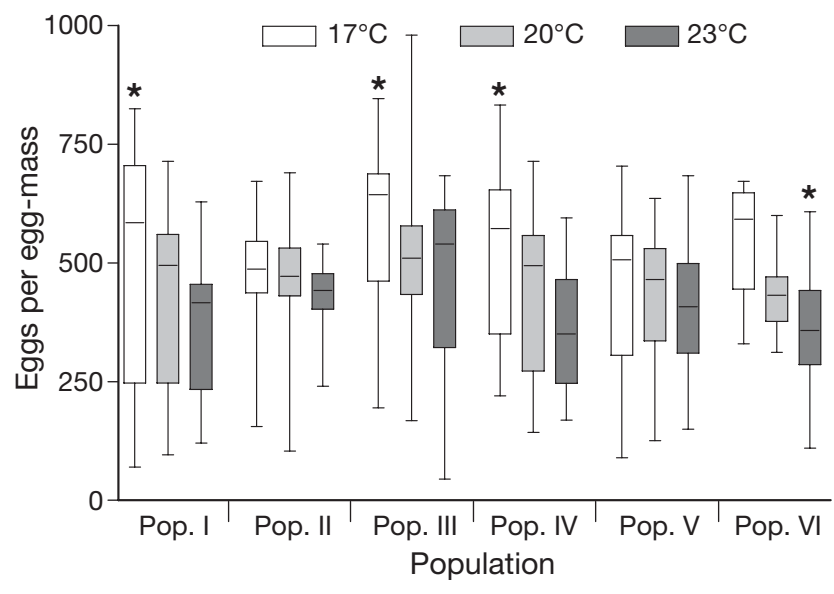

Fig. 3. Chironomus riparius. Median eggs per egg-mass (no. $\pm 25 / 75$ percentile, $\mathrm{n}=4-66$ ) of 6 genetically different populations (for descriptions see Table 1) within temperature treatments. ${ }^{*} \mathrm{p}<0.05$

diversity (Pop. I) and this population increased every day by about $50 \%$. For all populations (except Pop. VI), PGR was always above $1.2 \mathrm{~d}^{-1}$ and increasing temperatures led to an enhanced PGR.

\subsection{Genetic diversity of the offspring generation}

For Pop. I, hardly any effect of temperature stress on the genetic diversity of the F1 generation was observed compared to the parental generation (Fig. 6). Therefore, only a narrow range of $H_{e}$ (between 0.44 and 0.54) was found over all treatments. In contrast, Pop. IV exhibited a decline in the genetic diversity of

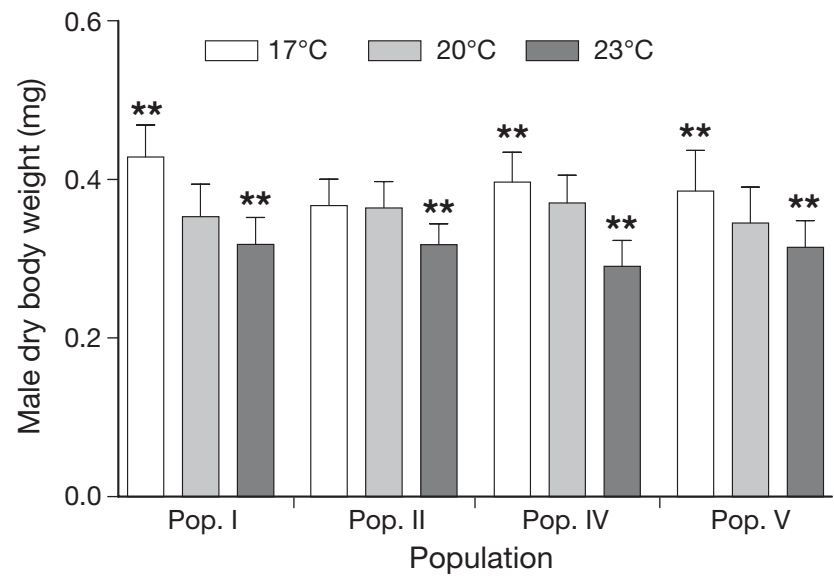

Fig. 4. Chironomus riparius. Mean male dry body wt (mg \pm SD) of Pop. I, II, IV and V (for population descriptions see Table 1) within temperature treatments. Significant differences were calculated using 1-way ANOVA (Dunnett's post hoc test), comparing treatments of 17 and $23^{\circ} \mathrm{C}$ with the standard temperature treatment of $20^{\circ} \mathrm{C} .{ }^{* *} \mathrm{p}<0.001, \mathrm{n}=46-67$ 


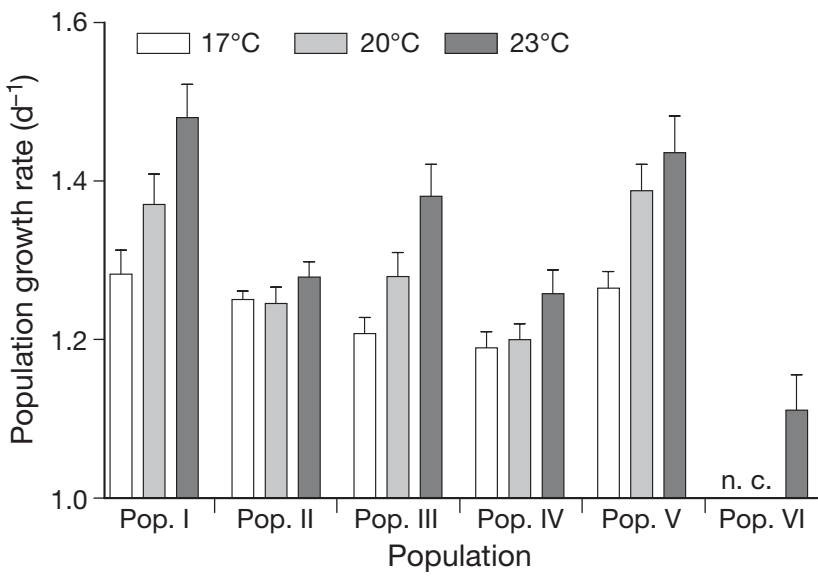

Fig. 5. Chironomus riparius. Population growth rate $\left(\mathrm{d}^{-1} \pm \mathrm{SD}\right.$; n.c.: not calculated due to insufficient reproduction) of 6 genetically different populations (for descriptions see Table 1) at 3 temperature treatments

the $\mathrm{F} 1$ generation at the highest temperature $\left(23^{\circ} \mathrm{C}\right)$, whereby the expected heterozygosity decreased from 0.23 (parental generation) to 0.09 (F1-generation).

\section{DISCUSSION}

Chironomus riparius was selected as a model organism and the results could to some degree be transferred to other species with a similar life cycle. Because of the wide temperature tolerance of chironomids, it can be assumed that field populations are not endangered by the chosen temperature shifts. Furthermore, chironomid field populations have a high genetic variability and they are not primarily endangered by genetic impoverishment. In the field, heterozygosities

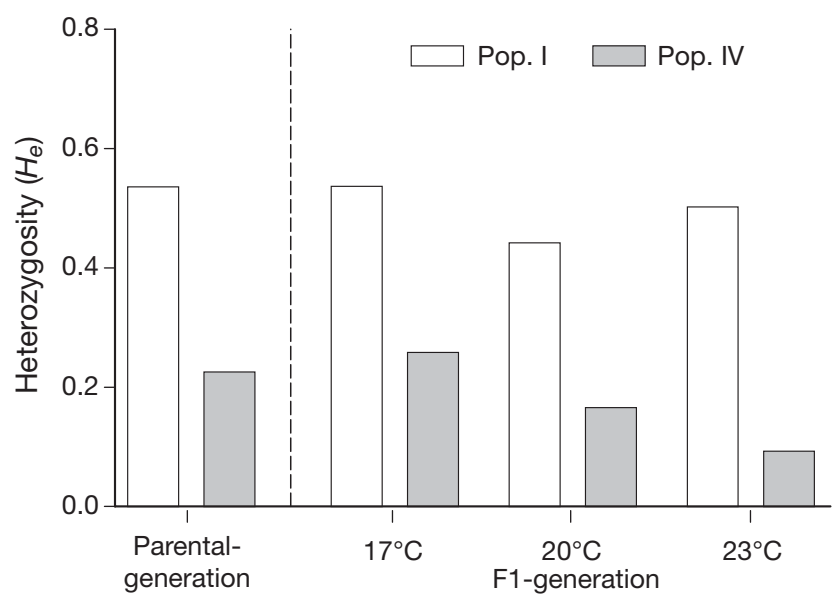

Fig. 6. Chironomus riparius. Expected heterozygosity $\left(H_{\mathrm{e}}\right)$ of the parental generation and F1 generation for Pop. I (white bars) and Pop. IV (grey bars) at 3 temperature treatments. For population descriptions see Table 1 around 0.6 were determined for 2 C. riparius populations in northern Baden-Württemberg, Germany (Nowak et al. 2007). The 3 populations in this study with the highest genetic diversity (Pop. I-III) represent a similar genetic diversity level to the field populations. The other 3 populations (Pop. IV-VI) with lower genetic variation could be understood as genetically impoverished populations due to their negative response to a disturbed situation. Pop. IV-VI can serve as examples for species which do not have such a high genetic diversity and which are more endangered by genetic impoverishment.

Significant effects of temperature stress were determined for various life-cycle parameters of Chironomus riparius. In general, mean emergence time, clutch size, dry body wt, and therefore population growth rate, were affected by temperature stress. The results are in good agreement with the results of similar studies on chironomids (Sankarperumal \& Pandian 1991, Stevens 1998, Frouz et al. 2002, Pery \& Garric 2006). In contrast, some parameters, such as the number of eggmasses per female (total and fertile), were not affected by temperature stress. The most probable effect of temperature at the selected range of 17 to $23^{\circ} \mathrm{C}$ is an increase in food uptake and assimilation during all 4 larval instars (Pery \& Garric 2006). The metabolic rate of the larvae increases with increasing temperature and they have a shorter larval development time (Sankarperumal \& Pandian 1991). These are the most probable reasons for the linear decrease of mean emergence time with increasing temperature. At $17^{\circ} \mathrm{C}$ the mean emergence time was $23 \mathrm{~d}$, and at $23^{\circ} \mathrm{C}$ the animals emerged after $15 \mathrm{~d}$, confirming the results of other studies (Goddeeris et al. 2001, Pery \& Garric 2006). Shorter larval development time due to higher temperatures leads to smaller imagines (Atkinson 1994, Surakarn \& Yano 1995, Frouz et al. 2002). This was also observed within our experiments.

The number of egg-masses per female and the fertility were only weakly affected by temperature, due to the effect of a decrease in pre-emergence time with increasing temperature. This was also observed in other studies with Chironomus riparius (Pery \& Garric 2006). Although for the number of egg-masses per female no effect of temperature was determined, the number of eggs per egg-mass was significantly decreased at higher temperatures. This phenomenon was also found for C. crassicaudatus, whereby females cultured at $17^{\circ} \mathrm{C}$ produced larger egg-masses compared to females cultured at $32.5^{\circ} \mathrm{C}$ (Xue \& Ali 1994). With the decreased mean emergence time at higher temperatures, the population growth rate also increases, compensating for the negative effect on the clutch size. The animals grow faster with e.g. an optimal food supply, and population growth rates above 
1.2 have also been observed in other studies (Lopes et al. 2005).

The investigation of temperature effect on genetic diversity provides a more differentiated picture than the single life cycle parameter analyses. Although for the F1-generation of Pop. I no temperature effect on genetic diversity was observed, the genetic variability of the F1-generation of Pop. IV was slightly decreased at $23^{\circ} \mathrm{C}$ compared to the parental generation (Fig. 6). The slight decrease of genetic variability within the F1-generation of Pop. IV could not be explained by higher mortalities in the parental generation. It could be explained by genetic drift (the most likely cause) or it might be due to a direct selection process, whereby only tolerant females are able to produce fertile offspring (Staton et al. 2001, Lopes et al. 2004).

A significant impact of genetic variability was determined for mortality, $\mathrm{EmT}_{50}$, eggs per egg-mass and the dry body wt. There was a tendency for populations with lower genetic diversity to produce fewer eggmasses per female (total and fertile), whereas temperature had no impact on this factor. Overall, populations with lower genetic diversity are endangered by temperature stress, whereby the intrinsic population growth rate rapidly decreases with temperature shifts. Populations with lower genetic variability have a lower potential to cope with changing environments (Frankham 2005b) and such populations are more sensitive to diseases and inbreeding depression (Hebert \& Luiker 1996, Reed et al. 2003).

\section{CONCLUSION}

Populations with reduced genetic diversity, e.g. as a result of low contaminant exposure (Vogt et al. 2007b), are threatened with extinction if a second stressor, such as slightly altered temperatures, comes into force. These results have considerable implications for the distribution and survival of locally distributed or rare species.

Acknowledgements. We thank the staff of the working groups Ecology and Evolution and Aquatic Ecotoxicology of the J. W. Goethe University for technical support. This research has been supported by the programme 'Environmental Quality and its Security and Sustainment' (BW-Plus) with funding from the State of Baden-Württemberg (project number BWR 22018).

\section{LITERATURE CITED}

Araujo MB, Rahbek C (2006) How does climate change affect biodiversity? Science 313:1396-1397

Armbruster P, Reed DH (2005) Inbreeding depression in benign and stressful environments. Heredity 95:235-242 Armitage PD, Cranston PS, Pinder LCV (1995) The Chirono- midae: biology and ecology of non-biting midges. Chapman \& Hall, London

Atkinson D (1994) Temperature and organism size: a biological law for ectotherms. Adv Ecol Res 25:1-58

Bickham JW, Sandhu S, Herbert PDN, Chikhi L, Athwal R (2000) Effects of chemical contaminants on genetic diversity in natural populations: implications for biomonitoring and ecotoxicology. Mutat Res-Rev Mutat 463:33-51

Dahlgaard J, Hoffmann AA (2000) Stress resistance and environmental dependency of inbreeding depression in Drosophila melanogaster. Conserv Biol 14:1187-1192

Frankham R (2005a) Genetics and extinction. Biol Conserv 126:131-140

Frankham R (2005b) Stress and adaptation in conservation genetics. J Evol Biol 18:750-755

Frouz J, Ali A, Lobinske RJ (2002) Influence of temperature on developmental rate, wing length, and larval head capsule size of pestiferous midge Chironomus crassicaudatus (Diptera: Chironomidae). J Econ Entomol 95:699-705

Goddeeris BR, Vermeulen AC, De Geest E, Jacobs B, Baert B, Ollevier F (2001) Diapause induction in the third and fourth instar of Chironomus riparius (Diptera) from Belgian lowland brooks. Arch Hydrobiol 150:307-327

Gong ZJP, Xie P, Li YL (2002) Effect of temperature and photoperiod on hatching of eggs of Tokunagayusurika akamusi (Tokunaga) (Diptera: Chironomidae). J Freshw Ecol 17: 169-170

Hall CJ, Burns CW (2002) Mortality and growth responses of Daphnia carinata to increases in temperature and salinity. Freshw Biol 47:451-458

Hansson B, Westerberg L (2002) On the correlation between heterozygosity and fitness in natural populations. Mol Ecol 11:2467-2474

Hauser TP, Loeschcke V (1996) Drought stress and inbreeding depression in Lychnis flos-cuculi (Caryophyllaceae). Evolution 50:1119-1126

Hebert PDN, Luiker MM (1996) Genetic effects of contaminant exposure-towards an assessment of impacts on animal populations. Sci Total Environ 191:23-58

Keller LF, Waller DM (2002) Inbreeding effects in wild populations. Trends Ecol Evol 17:230-241

Lopes I, Baird DJ, Ribeiro R (2004) Genetic determination of tolerance to lethal and sublethal copper concentrations in field populations of Daphnia longispina. Arch Environ Contam Toxicol 46:43-51

Lopes C, Pery ARR, Chaumot A, Charles S (2005) Ecotoxicology and population dynamics: using DEBtox models in a Leslie modeling approach. Ecol Model 188:30-40

Mitton JB (1997) Selection in natural populations. Oxford University Press, Oxford

Nowak C, Hankeln T, Schmidt ER, Schwenk K (2006) Development and localization of microsatellite markers for the sibling species Chironomus riparius and Chironomus piger (Diptera: Chironomidae). Mol Ecol Notes 6:915-917

Nowak C, Vogt C, Barateiro Diogo J, Schwenk K (2007) Genetic impoverishment in Chironomus cultures. Environ Toxicol Chem (in press)

OECD (2004) Sediment-water chironomid toxicity test using spiked sediment. Guideline for testing chemicals no. 218. Organisation for Economic Co-operation and Development, Paris

Olivier DR (1971) Life history of the Chironomidae. Annu Rev Entomol 16:211-230

Pery ARR, Garric J (2006) Modelling effects of temperature and feeding level on the life cycle of the midge Chironomus riparius: an energy based modelling approach. Hydrobiologia 553:59-66 
Pinder LCV (1986) Biology of freshwater Chironomidae. Annu Rev Entomol 31:1-23

Raymond M, Rousset F (1995) Genepop (version 1.2): Population-genetics software for exact tests and ecumenicism. J Hered 86:248-249

Reed DH, Lowe EH, Briscoe DA, Frankham R (2003) Inbreeding and extinction: effects of rate of inbreeding. Conserv Genet 4:405-410

Sankarperumal G, Pandian TJ (1991) Effect of temperature and chlorella density on growth and metamorphosis of Chironomus circumdatus (Kieffer) (Diptera). Aquat Insects 13:167-177

Staton JL, Schizas NV, Chandler GT, Coull BC, Quattro JM (2001) Ecotoxicology and population genetics: the emergence of 'phylogeographic and evolutionary ecotoxicology'. Ecotoxicology 10:217-222

Stevens MM (1998) Development and survival of Chironomus tepperi Skuse (Diptera: Chironomidae) at a range of constant temperatures. Aquat Insects 20:181-188

Surakarn R, Yano K (1995) Development of a paddy-dwelling

Editorial responsibility: Geir Ottersen,

Oslo, Norway chironomid, Chironomus kiiensis (Diptera, Chironomidae) under different temperatures. Jpn J Entomol 63: 389-398

Vogt C, Galluba S, Belz D, Nowak C, Oetken M, Oehlmann J (2007a) Effects of cadmium and tributyltin on development and reproduction of the non biting midge Chironomus riparius (Diptera): baseline experiments for future multi-generation studies. J Environ Sci Heal A 42:1-9

Vogt C, Nowak C, Barateiro Diogo J, Oetken M, Schwenk K, Oehlmann J (2007b) Multi-generation studies with Chironomus riparius - effects of low tributyltin concentrations on life-history parameters and genetic diversity. Chemosphere 67:2192-2200

Winnepenninckx B, Backeljau T, De Wachter R (1993) Extraction of high molecular weight DNA from molluscs. Trends Genet 9:407

Xue RD, Ali A (1994) Relationship between winglength and fecundity of a pestiferous midge, Glyptotendipes paripes (Diptera, Chironomidae). J Am Mosq Control Assoc 10: 29-34

Submitted: November 15, 2006; Accepted: March 8, 2007 Proofs received from author(s): April 16, 2007 